\title{
Dégradation in vitro des acides aminés de peptides de soja par un inoculum de bactéries du rumen et par Prevotella ruminicola
}

\author{
D Debroas, N Depardon, G Blanchart
}

INRA-ENSAIA, laboratoire de zootechnie, 54505 Vandoeuvre, France

Une étude réalisée sur la tryptone a mis en évidence le rôle du caractère hydrophobe ou hydrophile des peptides lors de leurs dégradations par les bactéries du rumen (Chen et al, 1987, Appl Environ Microbiol, 53, 2021). Par ailleurs, Yang et Russell (1992, Appl Environ Microbiol, 58, 3954) ont montré que les peptides synthétiques contenant de la proline étaient difficilement métabolisés par les bactéries. Le métabolisme des peptides semble donc dépendre de la composition en acides aminés. Afin de préciser le rôle de ceux-ci nous avons déterminé l'évolution de la composition en acides aminés de peptides de soja en présence d'un inoculum de bactéries du rumen ou de Prevotella ruminicola.

Les cultures bactériennes sont réalisées dans un milieu synthétique (Russell et al, 1983, J Dairy Sci, 66, 763-775) contenant des peptides de soja obtenus après une hydrolyse par la pronase $E$ (Depardon et al, 1994, Ann Zootech, 43, 269). Le milieu est distribué dans des tubes de Hungate. Ils sont ensemencés par un inoculum de bactéries du rumen ou de Prevotella ruminicola ( $\$ 23$ ou $\mathrm{S} 17 / 3$ ). Les tubes sont incubés à $39^{\circ} \mathrm{C}$. Le temps d'incubation est de $6 \mathrm{~h}$ pour un inoculum de bactéries du rumen et de $16 \mathrm{~h}$ pour les souches de Prevotella ruminicola. Régulièrement 3 tubes sont prélevés. Le milieu de culture est filtré sur $0,22 \mu \mathrm{m}$. Après hydrolyse acide $\left(22 \mathrm{~h}\right.$ à $110^{\circ} \mathrm{C}$ dans $\mathrm{HCl} 6 \mathrm{~N}$ ), les acides aminés sont dérivés selon la méthode de Husek (1991, J Chromatogr, 547, 289) en présence de deux étalons internes (norleucine et L-p-chlorophenylalanine). La séparation est réalisée par CPG (colonne capillaire OV1701) : $145^{\circ} \mathrm{C}$ à $205^{\circ} \mathrm{C}$ à $12,5^{\circ} \mathrm{C} / \mathrm{min}$, une montée en température de $5^{\circ} \mathrm{C} /$ min permet d'obtenir la température finale de $260^{\circ} \mathrm{C}$. Les résultats sont exprimés en $\%$ et sont traités par le test de Kruskal-Wallis.

Un changement dans la composition en thréonine, glutamate et glutamine (Glx) et en lysine $(P<0,10)$ est observé au cours de la fermentation par un inoculum de bactéries du rumen. Le résidu est enrichi en thréonine après $2 \mathrm{~h}$ de fermentation $(5,66 \%)$. A la fin de l'incubation, les peptides de soja ne contiennent plus que $3,58 \%$ de cet acide aminé. La proportion de Glx diminue au cours de la fermentation alors que la lysine qui est aussi un acide aminé hydrophile est dégradé plus lentement que les autres acides aminés. En effet, sa proportion qui est de $12,33 \%$ en début de fermentation représente $18,48 \%$ de la totalité des acides aminés dosés en fin d'incubation.

En présence de $P$. ruminicola $\$ 23$, les peptides sont enrichis en alanine. La proportion de cet acide aminé évolue de $5,84 \%$ à $8,31 \%$ $(P<0,10)$. Les proportions de Phe, lle et Leu varient au cours de l'incubation $(P<0,10)$. Cependant, les proportions de ces trois acides aminés dans le résidu en fin de phase exponentielle sont identiques à celles mesurées à $\mathrm{t}=0 \mathrm{~h}$. Lors d'une incubation en présence de $P$. ruminicola $\$ 17 / 3$, les proportions des acides aminés dans les résidus de fermentation ne varient pas.

La dégradation d'un substrat protéique présent dans l'alimentation des ruminants par un inoculum de bactéries du rumen et deux souches de $P$. ruminicola ne met pas en évidence un enrichissement préférentiel du résidu en acides aminés hydrophiles ou hydrophobes. Par ailleurs, la proportion de proline dans les résidus de fermentation ne varie pas significativement. 